\title{
Coexistence of Autonomic and Somatic Mechanisms in the Pressor Areas of Medulla in Cats
}

\author{
C. Y. CHAI, ${ }^{* 1}$ W. C. WU, ${ }^{*}$ S. WANG, ${ }^{*}$ C. K. SU, ${ }^{*}$ Y. F. LIN,${ }^{*}$ \\ C. T. YEN, $\dagger$ J. S. KUO $\neq$ AND M. J. WAYNER§ \\ *Institute of Biomedical Sciences, Academia Sinica, Taipei, Taiwan, ROC \\ tDepartment of Zoology, National Taiwan University, Taiwan, ROC \\ $\neq$ Department of Medical Research, Taichung Veterans General Hospital, Taiwan, $R O C$ \\ \$Division of Life Sciences, University of Texas at San Antonio, San Antonio, TX 78285
}

Received 20 May 1991

\begin{abstract}
CHAI, C. Y.. W. C. WU. S. WANG. C. K. SU. Y. F. LIN, C. T. YEN, J. S. KUO AND M. J. WAYNER. Coexistence of autonomic and somatic mechanisms in the pressor areas of medulla in cats. BRAIN RES BULL 29(1) 15-26, 1992. - The effects of electrical stimulation and microinjection of sodium glutamate $(0.5 \mathrm{M})$ in the sympathetic pressor areas of the dorsal medulla (DM), ventrolateral medulla (VLM), and parvocellular nucleus (PVC) on the knee jerk, crossed extension, and evoked potential of the L5 ventral root produced by intermittent electrical stimulation were studied in 98 adult cats anesthetized with chloralose and urethane. During electrical and glutamate stimulation of these pressor areas. in addition to the rise of systemic arterial blood pressure marked inhibition of the spinal reflex was produced, indicating presence of neuronal perikarya responsible for these actions. Mild to moderate augmentation of spinal reflexes was also observed during brain stimulation but only in a few cases. The magnitude of the somatic effects among the pressor areas of the VLM, DM, and PVC subsequent to glutamate activation was about the same. Induced spinal reflex inhibition, independent from the baroreceptor and vagal influence, remained essentially unaltered after acute midcollicular decerebration. The inhibition was also observed in cats decerebellated 8-10 davs in advance. The inhibition was not affected after bilateral electrolytic- or kainic-acid-induced lesions in the paramedian reticular nucleus (PRN). On the contrary, PRN-induced spinal reflex inhibition was attenuated after bilateral lesions in the DM or VLM. Data suggest that there coexists neuronal subpopulations in the VLM, DM, and PVC that can affect both the sympathetic pressor systems and spinal reflexes.
\end{abstract}

Spinal reflex Knee jerk Evoked ventral root potentials Medullary pressor mechanisms Dorsal medulla Ventrolateral medulla Parvocellular reticular nucleus

IN a previous study, we demonstrated the existence of a neuronal population in the paramedian reticular nucleus $(\mathrm{PRN})$ of the caudal medulla involved in a powerful inhibitory mechanism. Activation of this neuronal population not only suppressed the sympathetic vasomotor effects of asphyxia and intracranial pressure increase but also the somatomotor effects of muscular twitching subsequent to systemic picrotoxin (7). The somatomotor effects of PRN stimulation were further demonstrated by suppression of the knee jerk $(\mathrm{KnJ})$ and the $\mathrm{L} 5$ ventral ront evoked potential, produced by stimulating the sciatic or tibial afferents. The inhibition was found to be independent of the potentially reciprocal connections with the cerebellum (9).

The coexistence of a mechanism for somatic inhibition and sympathetic inhibition (depressor) in the same PRN structure suggested the possibility that the pressor areas of the medulla that affect sympathetic excitation similarly might also contain a mechanism augmenting spinal reflexes (4.5). Further support for this view comes from the activation of a sympathetic pressor mechanism in the locus coeruleus that augments spinal extensor and flexor monosynaptic reflexes evoked by stimulation of the common peroneal or posterior tibial nerve (12). Considerable evidence indicates the existence of a neuronal perikaryon mechanism in the sympathetic pressor area of the ventrolateral medulla (VI,M), particularly in the lateral reticular nucleus, that inhibits somatosympathetic reflexes, that is, evoked potentials recorded in the sympathetic white ramus produced by stimulation of various somatic afferents $(18,20,26)$.

The purpose of the present experiment was to study whether there also exists a neuronal subpopulation integrating spinal reflex-the Knj-and L5 ventral root reflex discharges in response

* Requests for reprints should be addressed to C. Y. Chai, Institute of Biomedical Sciences, Academia Sinica, Nankang 11529 , Taipei. Taiwan, ROC. 
TABLE 1

CHANGES IN SPINAL REFLEXES SUBSEQUENT TO BARORECEPTOR INFLUENCES AND STIMULATION OF THE SYMPATHETIC PRESSOR AREAS OF THE MEDULLA

\begin{tabular}{|c|c|c|c|c|}
\hline & \multirow[b]{2}{*}{ SAP Changes $(\%)$} & \multicolumn{3}{|c|}{ Leg Movement } \\
\hline & & KпJ $(\%)$ & CEM $(\%)$ & EVRR $(\%)$ \\
\hline \multicolumn{5}{|c|}{$\begin{array}{l}\text { Changes of spinal reflexes } \\
\text { consequent to } \\
\text { baroreceptor effects }\end{array}$} \\
\hline $\begin{array}{l}\text { NP (25) } \\
\text { Epi }(20)\end{array}$ & $\begin{array}{l}-42.7 \pm 1.8^{*} \\
+55.3 \pm 4.5^{*}\end{array}$ & $\begin{array}{l}-73.6 \pm 3.4^{*}(22) \\
+52.5 \pm 13.9^{*}(16)\end{array}$ & $\begin{array}{l}-73.9 \pm 4.8^{*}(22) \\
+64.5 \pm 19.5^{*}(16)\end{array}$ & $\begin{array}{l}-44.7 \pm 8.7^{*}(3) \\
+66.5 \pm 20.7^{*}(4)\end{array}$ \\
\hline \multicolumn{5}{|c|}{$\begin{array}{l}\text { Changes of spinal reflexes } \\
\text { consequent to brain } \\
\text { stimulation }\end{array}$} \\
\hline \multicolumn{5}{|c|}{$\begin{array}{l}\text { Animals with intact baroreceptor } \\
\text { mechanism } \\
\text { DM }\end{array}$} \\
\hline $\begin{array}{l}\text { E } \\
\text { Glu (57) }\end{array}$ & $\begin{array}{l}+49.2 \pm 3.4^{*} \\
+10.4 \pm 3.5^{*}\end{array}$ & $\begin{array}{l}-63.2 \pm 3.3^{*} \\
-65.7 \pm 4.6^{*}(45)\end{array}$ & $\begin{array}{l}-75.9 \pm 3.9^{*} \\
-70.4 \pm 4.7^{*}(45)\end{array}$ & $\begin{array}{l}-50.4 \pm 7.0^{*} \\
-45.4 \pm 7.9^{*}(12)\end{array}$ \\
\hline \multicolumn{5}{|l|}{ VLM } \\
\hline $\begin{array}{l}\text { E } \\
\text { Glu (24) }\end{array}$ & $\begin{array}{l}+45.3 \pm 4.5^{*} \\
+14.2 \pm 5.0^{*}\end{array}$ & $\begin{array}{l}-75.7 \pm 8.7^{*} \\
-64.8 \pm 7.0^{*}(11)\end{array}$ & $\begin{array}{l}-79.5 \pm 9.6^{*} \\
-64.9 \pm 10.9^{*}(11)\end{array}$ & $\begin{array}{l}-56.1 \pm 4.2^{*} \\
-43.0 \pm 6.8^{*}(13)\end{array}$ \\
\hline \multicolumn{5}{|l|}{ PVC } \\
\hline $\begin{array}{l}\text { E } \\
\text { Glu }(10)\end{array}$ & $\begin{array}{l}+58.1 \pm 13.2^{*} \\
+10.6 \pm 2.0^{*}\end{array}$ & $\begin{array}{l}-59.7 \pm 10.1^{*} \\
-71.3 \pm 14.9^{*}(4)\end{array}$ & $\begin{array}{l}-61.7 \pm 15.5^{*} \\
-76.7 \pm 16.3^{*}(4)\end{array}$ & $\begin{array}{l}-47.6 \pm 6.3^{*} \\
-42.0 \pm 9.8^{*}(6)\end{array}$ \\
\hline \multicolumn{5}{|c|}{$\begin{array}{l}\text { Animals with carotid sinus } \\
\text { nerves cut and vagotomy }\end{array}$} \\
\hline \multicolumn{5}{|c|}{ DM } \\
\hline E & $+93.3 \pm 17.7^{*}$ & $-52.0 \pm 13.5^{*}$ & $-72.0 \pm 7.3^{*}$ & \\
\hline Glu (6) & $+11.3 \pm 10.9$ & $-88.0 \pm 8.6^{*}$ & $-97.0 \pm 2.9^{*}$ & \\
\hline \multicolumn{5}{|l|}{ VLM } \\
\hline E & $+66.1 \pm 5.6^{*}$ & & & $-28.5 \pm 4.9^{*}$ \\
\hline Glu (6) & $+42.8 \pm 8.0^{*}$ & & & $-31.2 \pm 7.2^{*}$ \\
\hline
\end{tabular}

Here and in Table 2, all results are presented as means \pm SEM. Number in parentheses = number of experiments performed. SAP, systemic arterial blood pressure; $\mathrm{KnJ}$, knee jerk; CEM, crossed extensor movement; EVRR, evoked ventral root response (ipsilateral side); NP. nitroprusside $20 \mu \mathrm{g} / \mathrm{kg}$, IV; Epi, epinephrine $8 \mu \mathrm{g} / \mathrm{kg}$, IV; VLM, ventrolateral medulla; DM, dorsal medulla; PVC, parvocellular reticular nucleus; E, electrical stimulation; Glu, glutamate microinjection.

* Values before and after electrical (E) or glutamate (Glu) stimulation of the brain are statistically significant. calculated by Student's $t$-test with $p$ values $<0.05$ (Table 2 also).

to stimulation of the sciatic or tibial nerve afferents in the pressor areas of the VLM, dorsal medulla (DM), and parvocellular nucleus (PVC) that resides in the neuronal population integrating sympathetic pressor action. Preliminary data have been reported elsewhere (11).

\section{METHOD}

Ninety-eight cats of either sex, weighing $2-3.6 \mathrm{~kg}$, anesthetized with a mixture of urethane $(400 \mathrm{mg} / \mathrm{kg})$ and $\alpha$-chloralose $(40$ $\mathrm{mg} / \mathrm{kg}$ ) intraperitoneally were used. The general procedures for experimentation have been described previously $(8,10,38)$. These included cannulation of the right femoral artery for monitoring the systemic arterial blood pressure (SAP) and the mean SAP (MSAP), which triggers the heart rate, cannulation of the right femoral vein for drug injections, tracheal intubation for artificial ventilation maintaining the end-expiratory $\mathrm{CO}_{2}$ concentration at $4 \%$, and keeping the rectal temperature at $37.5^{\circ} \mathrm{C}$ by a thermocontrolled heating pad. All recordings were made on a Gould ES 1000 recorder or taped for later analysis.

\section{Spinal Reflexes}

The general method for producing spinal reflexes has been described previously $(6,9)$.

Gross movement of $\mathrm{KnJ}$ and cross extension. Both hind legs were stabilized by mounting two copper pins to the femurs and then attaching the pins to two metal stands. The quadriceps on both legs were then isolated and connected to a Gould forcedisplacement transducer (F103D) to monitor muscle contraction.

Evoked ventral root response (EVRR). The animal was paralyzed by atracurium besylate $(0.5 \mathrm{mg} / \mathrm{kg} / 30 \mathrm{~min}$. IV) as a supplement to the general anesthesia. The spinal cord from L4-L6 was exposed with the help of a David-Kopf spinal investigation unit. The exposed spinal cord and nerves were immersed in paraffin oil. The ventral rootlets at L5 were cut and its central end was hooked on a bipolar hook platinum electrode for recording the evoked potentials. The signals were amplified with a WPI DAM-60 preamplifier and Gould universal amplifier (band pass: $1-3 \mathrm{kHz}$ ). Afterward, signals were displayed on a storage oscilloscope (Tektronix 5113). All recordings were taped 

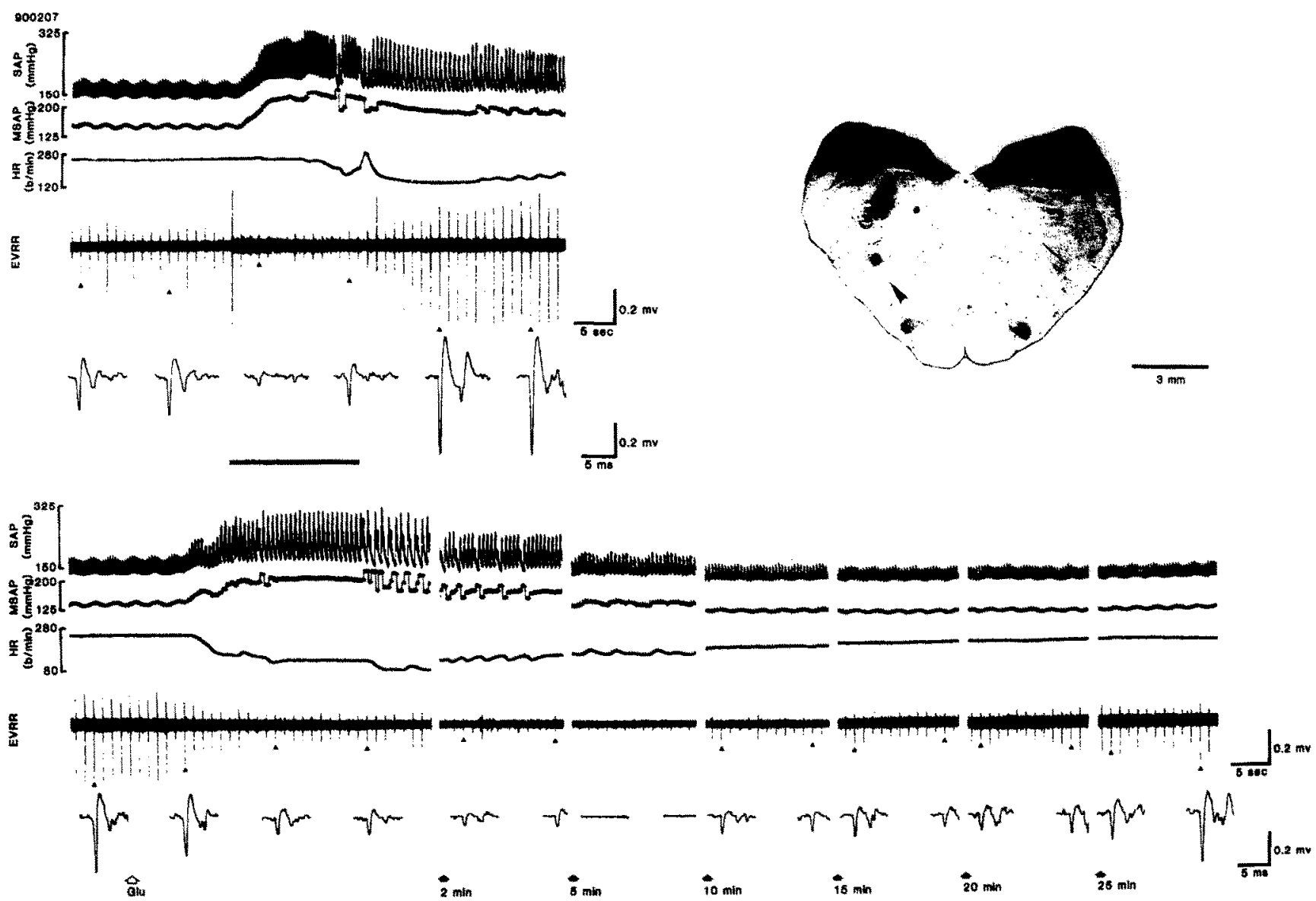

FIG. 1. Effects of VLM stimulation on EVRR. From this and the following figures, traces from top to bottom, systemic arterial blood pressure (SAP), mean SAP (MSAP), heart rate (HR), and evoked ventral root response (EVRR) and the expanded EVRR picked up from a specific EVRR indicated by arrowheads (A). (-) and $(\boldsymbol{C})$, time period of delivering electrical stimulation and the site of microinjection of chemicals, respectively. Upper panels show that electrical stimulation $(100 \mu \mathrm{A})$ of a point in VLM, indicated by the arrowhead on the histological section of the medulla $4 \mathrm{~mm}$ rostral to the obex, produced marked increase of SAP, decrease of HR, and an initial reduction followed by augmentation of EVRR. Note that microinjection ( $100 \mathrm{nl}$ ) of glutamate (Glu, $100 \mathrm{nl}$ ) to the stimulating site (lower panels) produced similar but more prolonged cardiovascular responses and reduced EVRR.

by an HP 3968A tape recorder for later analysis. On-line analysis of the EVRR was made by expanding and displaying the evoked potential on the polygraph through a waveform module (Gould, waveform $100 \mathrm{kHz}$ ).

Two forms of spinal reflex activity, that is, the gross leg movement of $\mathrm{KnJ}$ and cross extension and EVRR, were produced by intermittent stimulation (rectangular pulse: $100-1200$ $\mu \Lambda, 1 \mathrm{~ms}, 1 \mathrm{~Hz}$ ) of the central end of the ipsilateral sciatic or tibial nerve. Four components of the EVRR were observed: the short latency $(2.5 \mathrm{~ms})$ of component 1 and the long latency of components $2(4.5 \mathrm{~ms}), 3(9.0 \mathrm{~ms})$, and $4(20.0 \mathrm{~ms})$. Only components $I$ and 2 were retained and amplified for illustrations in the figures and the amplitude of component 2 was measured to determine the change in spinal reflex intensity.

Rectangular pulses were provided by a constant-current unit connected to a Grass S-88 stimulator. For brain stimulation, rectangular pulses (1-ms pulse duration, $100-200 \mu \mathrm{A}$ amplitude at $80 \mathrm{~Hz}$ ) were delivered for $15 \mathrm{~s}$. As previously described (8), the electrical-stimulating monopolar electrode, 30-ga stainless steel needle tubing, electrically insulated except for a minute area at the tip, was also used for electrical stimulation or microinjection of monosodium glutamate (Glu, $0.5 \mathrm{M}, \mathrm{pH} 7.4$, $1 \%$ fast green in artificial cerebrospinal fluid) (13). We found that glutamate at this concentration (21) could repeat a pressor action of unaltered intensity in the pressor areas of medulla at an interval of $30 \mathrm{~min}$.

To determine whether the spinal reflexes induced by medullary stimulation depend upon the integrity of rostral brain structures and cerebella, the following procedures were carried out and the responses of medullary stimulation before and after the procedures were compared: (1) rostral neural structuresmidcollicular decerebration (39) was performed with ligation of both external carotid arteries and clamping of the basilar artery; (2) cerebella-the whole cerebellum were suctioned under aseptic procedures and animals cared for 7-14 days for good recovery and degeneration of the afferent and efferent fibers before subjected to spinal reflex study (7).

Localized brain lesion was made by either microinjection of kainic acid ( $\mu \mathrm{g}$ in $200 \mathrm{nl}$ saline) into the brain or passing direct current $(0.5 \mathrm{~mA}, 30 \mathrm{~s})$. Kainic acid destroys principally perikaryon (40) but sparing axon, while direct current destroys both perikaryon and axons. In either case, the stimulating point plus two additional points, $1 \mathrm{~mm}$ rostral and caudal to the latter, were lesioned as reported previously (38).

Stimulation of the cardiovascular areas in the medulla produced changes (increase or decrease) of SAP and heart rate that 

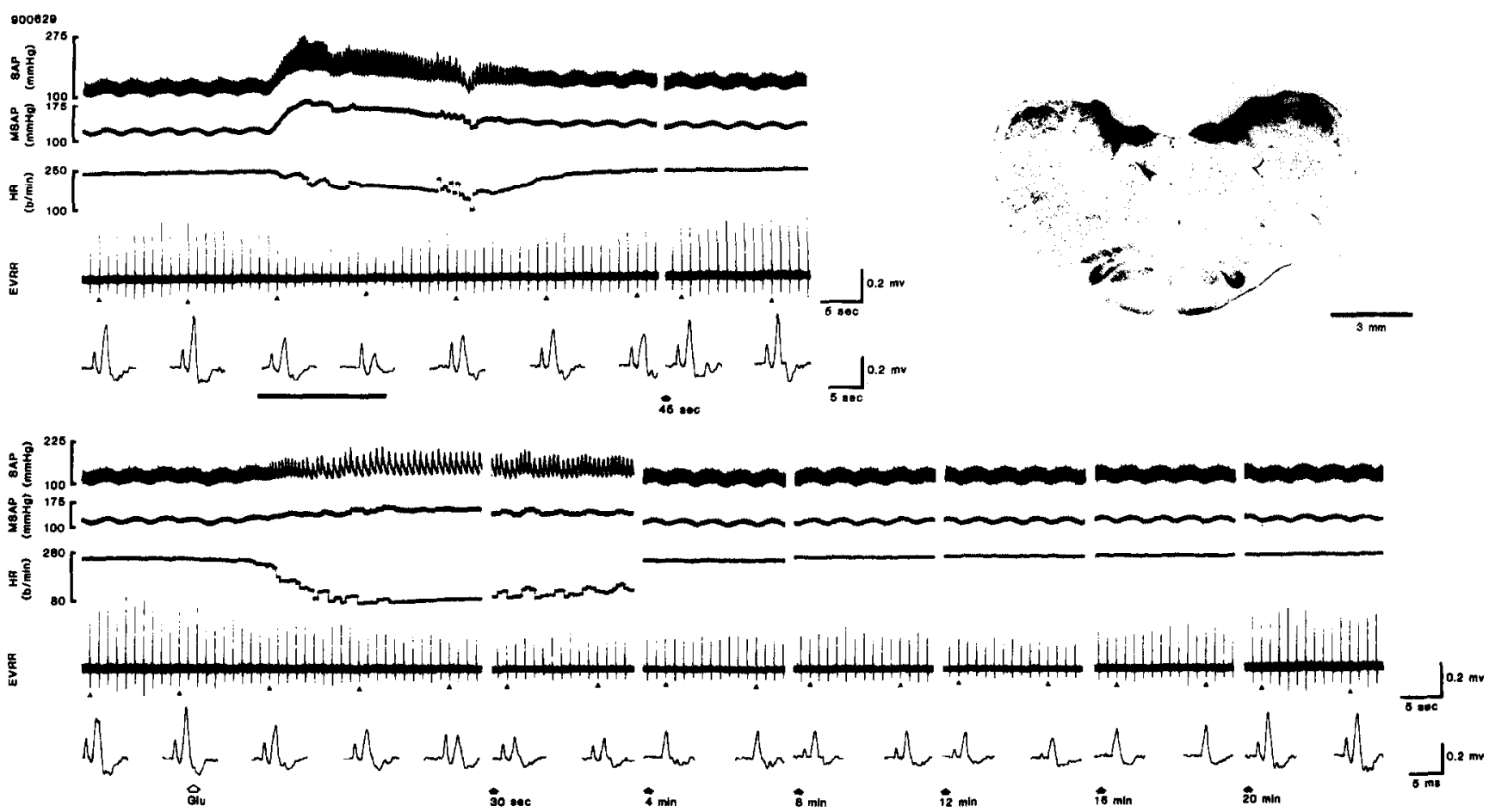

FIG. 2. Effects of DM stimulation on EVRR. Note the similarities of both cardiovascular and spinal reflex responses between electrical stimulation (100 $\mu \mathrm{A}$, upper panels) and Glu microinjection (100 nl, lower panels) at a point in the DM, $3 \mathrm{~mm}$ rostral to the obex as shown in the histological section. Note also the more prolonged actions of Glu activation.

may activate or inactivate baroreceptor reflex. The latter effects were mimicked by IV administration of pressor agent, epinephrine $8 \mu \mathrm{g} / \mathrm{kg}$, or depressor agent, nitroprusside $20 \mu \mathrm{g} / \mathrm{kg}$. The influence of baroreceptor reflex was eliminated by IV administration of an $\alpha$-blocking agent, phentolamine $0.4 \mathrm{mg} / \mathrm{kg}$, or by prior denervation of both carotid sinus nerve by the conventional method plus bilateral vagotomy (including aortic nerves) at the cervical level. The vagal effects were eliminated by cervical vagotomy on both sides.

\section{Histology}

At the end of each experiment, the animal was killed with an overdose of pentobarbital. The brain was removed and fixed in $10 \%$ formalin; the chemical injection sites were verified using consecutive sections, one stained with cresyl violet for identifying nuclei and the other unstained for determining the position and diffusion of dye.

\section{Data Analysis}

In the series of experiments, when treatments included intravenous injection of the pressor and/or depressor agent and brain stimulation in either baroreceptor-intact or -inactivated cats the percent changes of SAP, KnJ, crossed extensor movement (CEM), and EVRR from the control levels were calculated and grouped according to their respective treatments. Student's $t$-test was used to verify the statistical significance of the effectiveness of each treatment. The mean percent change of each response from its control level was tested against a hypothesis that the percent change before the treatment was zero. $p<0.05$ was considered significant.

In another series of experiments, the effects before and after brain lesion on the responses elicited by electrical stimulation of another area in the brain were compared in the same animals by paired Student's $t$-test. On the other hand, to compare the effects of lesioning different brain areas on the responses clicited by electrical stimulation of a specific brain area the corresponding control groups were pooled. For instance, the responses of PRN stimulation before VLM or DM lesion were pooled to a common control. A one-way analysis of variznce (ANOVA) was performed on the group means and a method of comparison by pairs (32) was used to test the statistical significance $(p<0.05)$.

\section{RESULTS}

\section{Effects of Activation of the Pressor Areas of the Medulla on Spinal Reflexes}

Inhibition of spinal reflexes. The spinal reflexes inhibition, in terms of leg movements or EVRRs, produced by both electrical and chemical stimulations in brain sites, 57 in DM, 24 in VLM, and 10 in PVC, is illustrated in Table $I$ and Figs. $I$ and 2. Differences in onset and duration of the induced response were observed between electrical and glutamate activation. Upon clectrical stimulation, the onset of response in both SAP increase and spinal reflex inhibition was fast $(0.5-1 \mathrm{~s})$, but the duration of the responses was short (varied from 1-2 min). During the period of electrical stimulation, concomitant with the SAP rise the heart rate might not be changed, slightly increased, or gradually declined, but in many instances marked and abrupt bradycardia might occur right after the stimulation was terminated (compare Figs. 1 and 2). Upon glutamate microinjection, the onset of response was slow (usually 5-10 s). For those points where the magnitude of glutamate-induced SAP rise was comparable to that of electrical stimulation, indicating that the injection site was very close to the perikarya, the onset varied from $1-3 \mathrm{~s}$ and the duration of responses lasted longer and varied 
A 7

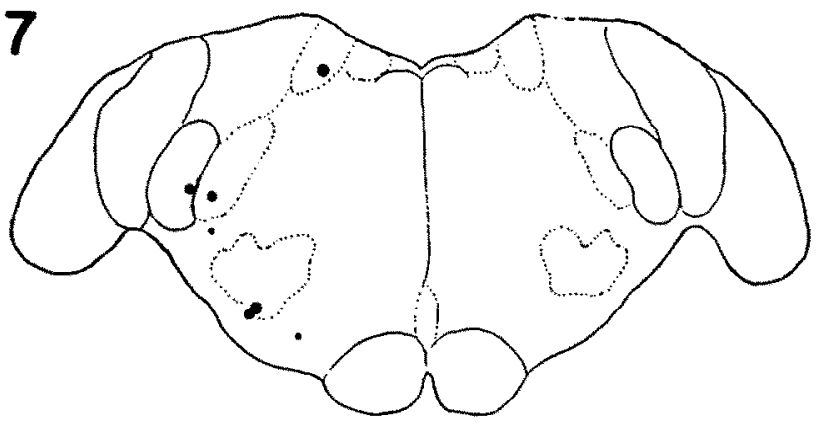

A 6

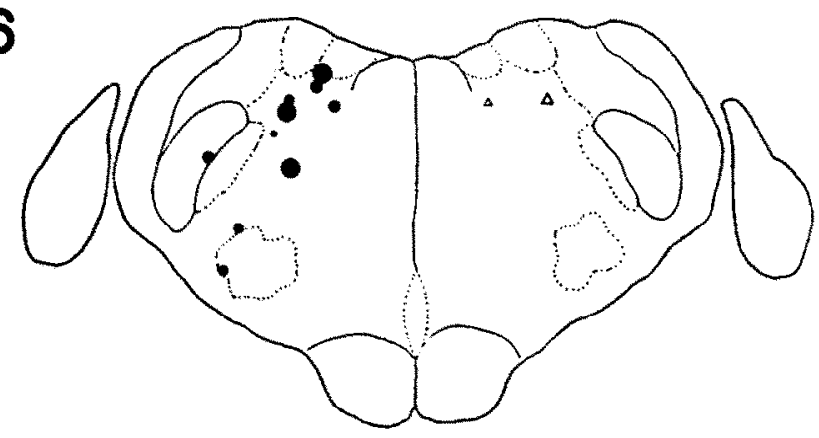

A 5

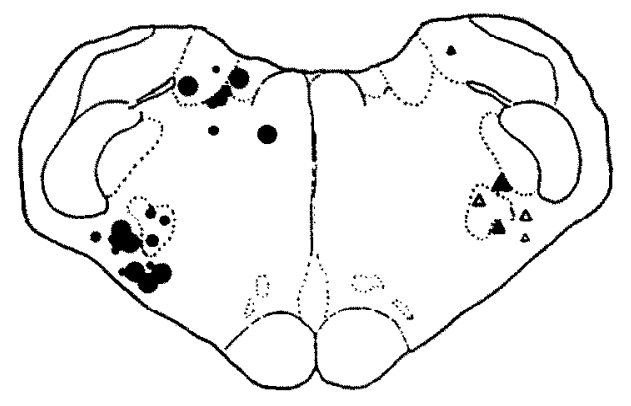

\section{A 4}

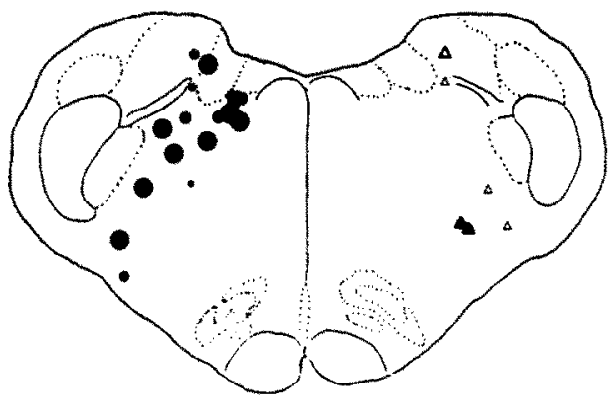

$3 \mathrm{~mm}$
A 3

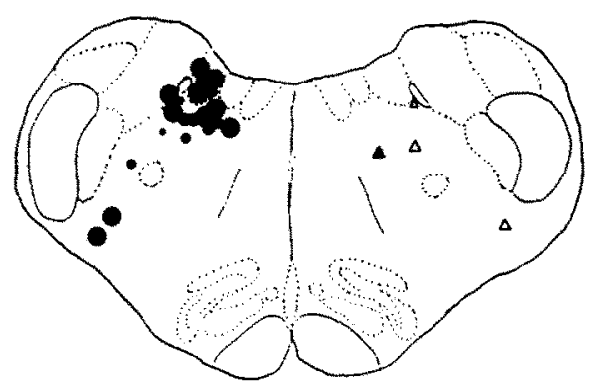

A 2

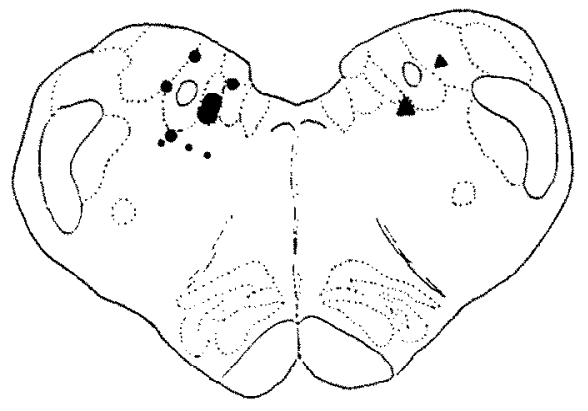

A 1

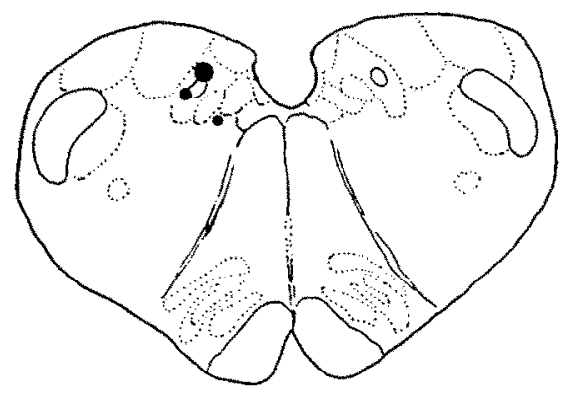

OBEX

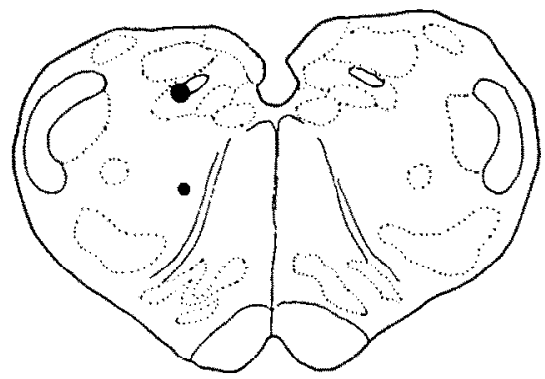

FIG. 3. Distribution of points affecting spinal reflexes in the sympathetic pressor areas of the medulla from levels of the obex to $7 \mathrm{~mm}$ rostral (A7) to the latter structure. Points that caused inhibition of the reflexes are mapped on the left half of the brain drawing. Four different sizes of solid circles (O - *) are used to express the extent of reflex reduction in decreasing order from 70-100\%, 50-70\%, 20-50\%, and 1-20\%, respectively. Points that caused augmentation of spinal reflexes are mapped on the right half of the brain drawing. Three sizes of triangles ( $\boldsymbol{\Delta} \boldsymbol{\Delta} \boldsymbol{\Delta})$ are used to express the extent of spinal reflex augmentation in decreasing order from above $50 \%, 20-50 \%$, and $1-20 \%$, respectively. The points where electrical and 61 . stimulation produced the same responses are represented by solid triangles in contrast to the points represented by empty triangles, where only electrical stimulation produced augmentation of the spinal reflexes. 


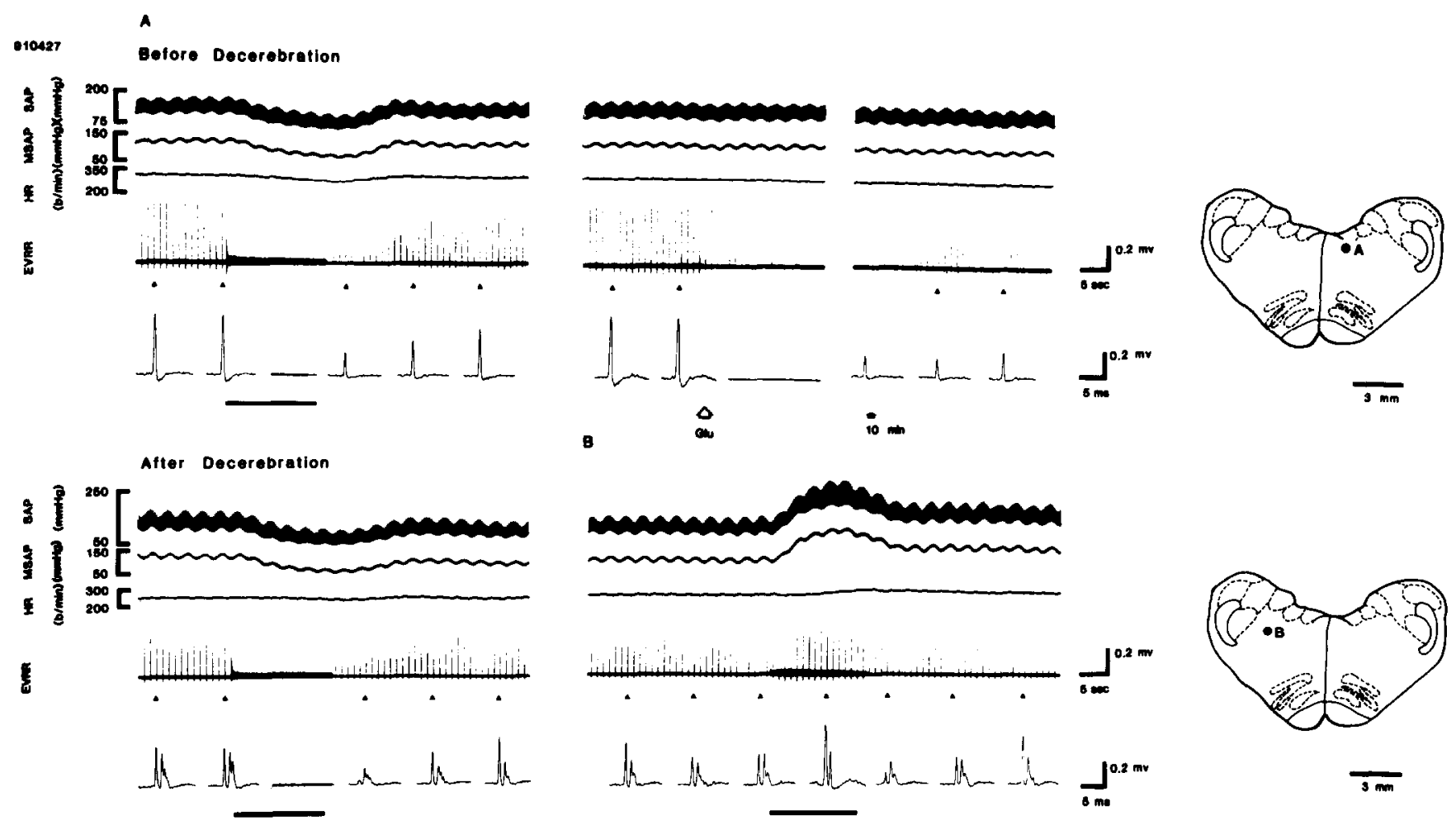

FIG. 4. Effects of decercbration on the spinal reflex inhibition due to DM or PVC activation. Upper panels show that electrical $(\Lambda$ left, $100 \mu \Lambda)$ and Glu (A right, $200 \mathrm{nl}$ ) stimulation of a point in the DM, as shown by the dot (A) on the brain drawing on the right, produced hypotension and inhibition of the EVRR. Lower panels on the left show that after midcollicular decerebration electrical stimulation of the same point (A) in DM with the same intensity produced similar hypotension and reduction of the EVRR. Lower panels on the right show that in the decerebrate animal stimulation $(100 \mu \mathrm{A})$ of a point (B) in the parvocellular nucleus, as shown by the brain drawing on the right, produced hypertension and increase in the EVRR.

from 5-25 $\mathrm{min}$. In this type of response, bradycardia usually occurred immediately concomitant with the pressor rise. This phenomenon was particularly obvious when the injection sites were near the vagal components; dorsal motor nucleus of the vagus or ambiguous nucleus (Figs. 1 and 2 ).

Nevertheless, electrical and glutamate stimulation produced little difference in the magnitude of spinal reflex inhibition. During glutamate activation, the EVRR inhibition in the VLM, DM, and PVC was 43.0, 45.4, and $42.0 \%$, respectively.

Figure 3 shows the composite map of the points responsive to both electrical and glutamate stimulation. It can be seen that the points in the VLM fell in the regions of the lateral reticular nucleus, retrofacial nucleus, and ambiguus complex. In the DM, the points were scattered around the regions of the nucleus of the tractus solitarius, dorsal motor nucleus of the vagus, hypoglossal nuclcus, vestibular nucleus, and latcral tegmental ficld of the PVC area.

The effect of spinal reflex inhibition consequent to activation of the pressor mechanism of the DM or VLM did not depend upon the integrity of the rostral neural structures since acute midcollicular decerebration (seven cats) did not significantly alter spinal reflex inhibition. Sometimes, stimulation of the depressor mechanism might also produce inhibition of spinal reflexes of EVRR reduction (Fig. 4). The spinal reflex inhibition resulting from depressor area activation was not affected by decerebration either.

The inhibition of spinal reflexes due to stimulation of the pressor areas of the medulla does not depend upon the integ- rity of the cerebella. In six chronically decerebellated cats, stimulation of the DM, VLM, or PVC produced inhibition of spinal reflexes, and the extent of inhibition was not much different in comparison with those of intact animals.

The amplitude of the SAP rise and bradycardia concomitant with stimulation of the medullary pressor areas was not a determinative factor for the degree of induced spinal reflex inhibition. A typical example (Fig. 5) is shown to illustrate this effect. In this example, electrical stimulation of a point (A) in PVC produced a marked SAP rise and moderate bradycardia, yet the induced EVRR remained unchanged. Stimulation of a point (B) in VLM, one $\mathrm{mm}$ ventral to $\mathrm{A}$, produced a much smaller SAP rise and practically no bradycardia, yet marked inhibition of EVRR occurred.

The integrity of the vagus nerve was not essential for the inhibition of spinal reflexes. In four animals, the spinal reflex inhibition due to DM or VLM stimulation was compared before and after bilateral vagotomy. After vagotomy, except for the augmentation of the pressor response and abolition of the reflex bradycardia the spinal reflex inhibition induced by activation of the pressor areas of the medulla was essentially unaltered.

Augmentation of spinal reflexes. During the course of medullary stimulation, four points in DM and four points in VLM were found to increase the EVRR when stimulated either electrically or by glutamate (Figs. 3 and 6 ). In another 12 points, 6 each in the VLM and the DM, electrical stimulation produced an increase while glutamate decreased the EVRR, whereas both types of stimulations produced an SAP increase (Fig. 7). 


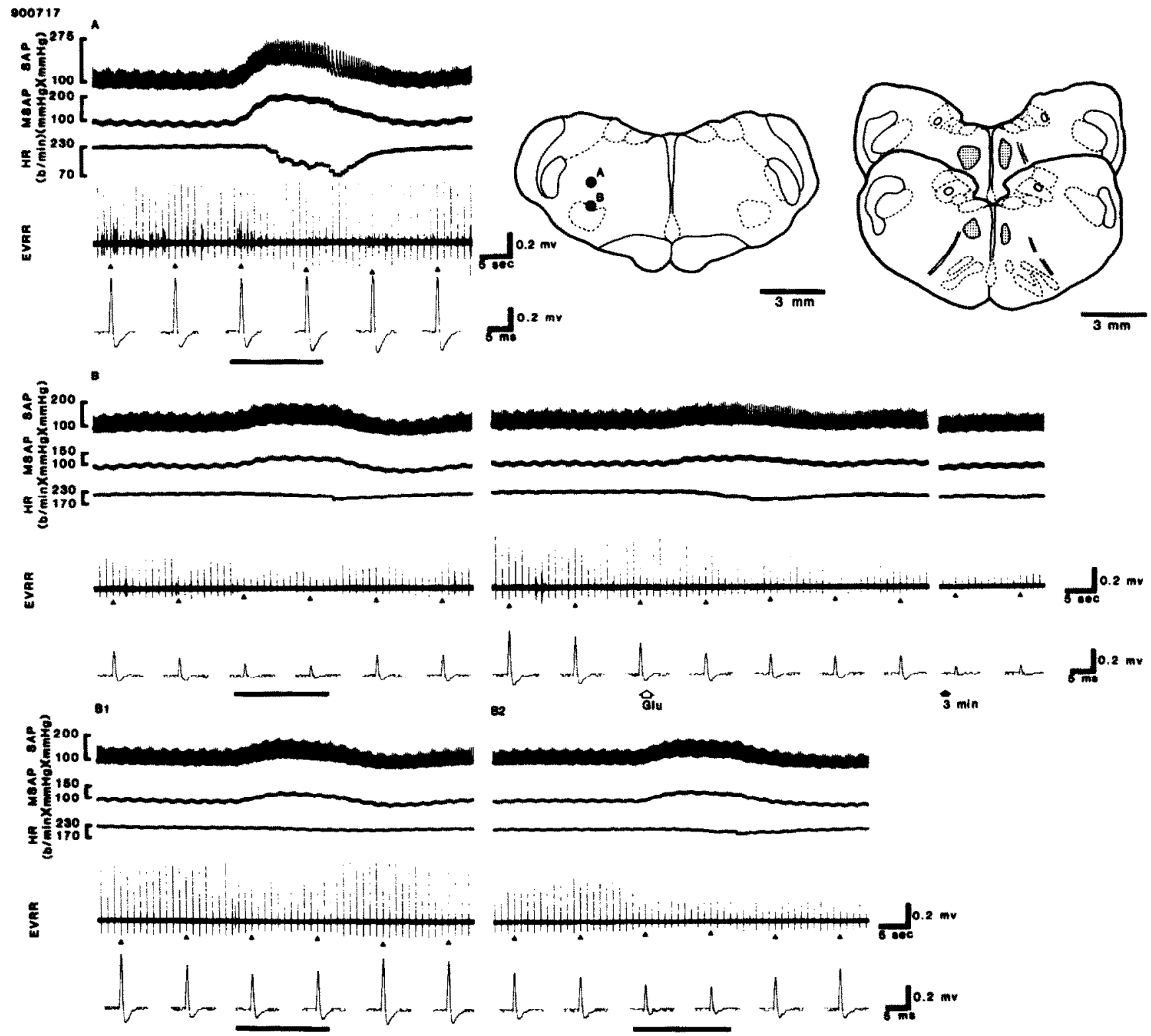

FIG. 5. The spinal reflex inhibition consequent to PVC or VLM activation is independent from the amplitude of the SAP rise and the integrity of paramedian reticular nucleus. Upper panels show that electrical stimulation $(100 \mu \mathrm{A})$ of a point $(\mathrm{A})$ in PVC, $4 \mathrm{~mm}$ rostral to obex as shown in the brain drawing, produced a marked elevation of SAP but no reduction of EVRR. Injection of Glu at this point did not produce change in SAP or EVRR (data not shown). Activation of a point (B) at VLM $1 \mathrm{~mm}$ ventral to point (A) on the same level with the same electric current (middle panels, B, left) or microinjection of Glu ( $100 \mathrm{nl}$, middle panel, B, right) produced marked reduction of EVRR despite little SAP rise. The PRN area on either side, previously identified by their depressor responses (data not shown) was then lesioned (DC $0.5 \mathrm{~mA}$ for $30 \mathrm{~s}$ ). After the lesion. the VLM-induced EVRR inhibition was slightly attenuated (bottom panels, B1, left), but recovered 10 min later (bottom panels, B2, right).

Two separate points in the VLM and DM produced augmentation of the EVRR. Lesioning an area involving both the PRN and the dorsomedial area close to the nucleus of the tractus solitarius (NTS) did not affect the EVRR augmentation. Figure 7 shows the EVRR augmentation upon VLM stimulation.

\section{Effects of Baroreceptor Activity on Induced Spinal Reflexes}

Because stimulation of the pressor areas of the medulla produced marked elevation of SAP that inevitably activated the baroreceptor reflex, the effects of SAP elevation or reduction produced by IV epinephrine $(8 \mu \mathrm{g} / \mathrm{kg})$ or nitroprusside $(20 \mu \mathrm{g} /$ $\mathrm{kg}$ ) on the induced spinal reflexes were studied (Table 1). It was found that $S A P$ reduction produced a uniform decrease in the EVRR by $44.7 \%$. Among the 20 instances of SAP elevation following epinephrine injection in different animals, the spinal reflex was uniformly increased in 12 cases during the whole course of SAP rise. In the remaining eight instances, EVRR was increased only in the initial period of the SAP rise and then decreased subsequently. Taken as a whole, EVRR increased by $66.5 \%$. 

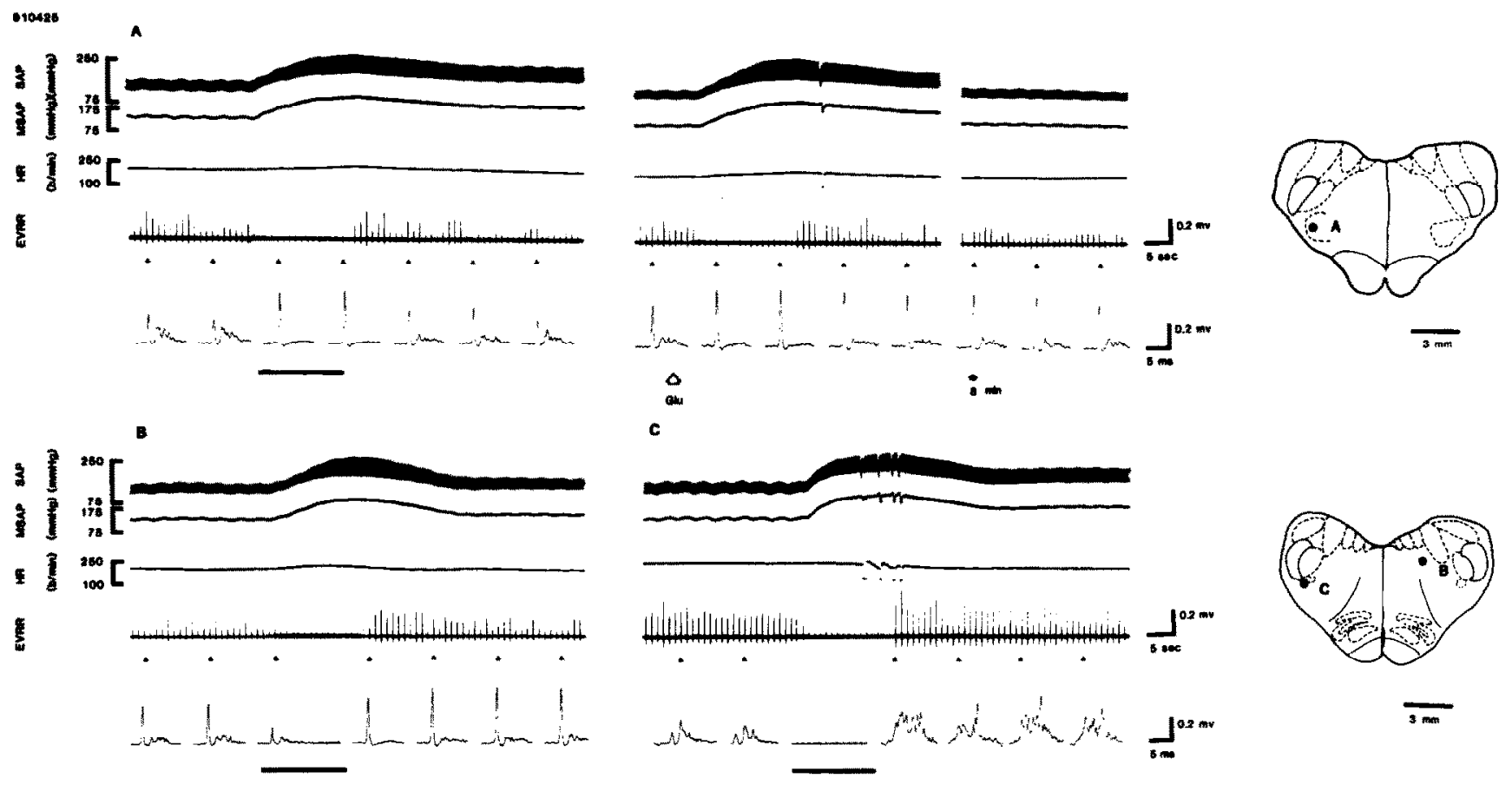

FIG. 6. Stimulation of the pressor areas of DM and VLM produced increase or decrease of spinal reflex. Top panels show that electrical (150 $\mu A$, left) and Glu (200 nl, right) stimulation of a point (A) in VLM produced an increase of SAP and augmentation of the EVRR. On the other hand, as shown in the lower panels, electrical stimulation $(100 \mu \mathrm{A})$ of two separate points, $(B)$ in the DM and $(C)$ in the VLM, produced an increase of SAP but reduction of EVRR.

In five animals, the effects of prior administration of phentolamine $(0.4 \mathrm{mg} / \mathrm{kg}$. IV), an $\alpha$-blocking agent, on the EVRR were studied. It was found that when the sympathetic pressor responses were blocked, and with the subsequent inactivation of the baroreceptor reflex, the spinal reflex inhibition produced by stimulation of the same DM or VLM pressor area did not change (Fig. 8).

In six animals, the carotid sinus nerves on both sides were cut, plus by painting $10 \%$ carbonic acid on the carotid sinus and vagotomy to severe the aortic nerve. The reduced EVRR after DM and VLM stimulation by both electrical current and glutamate were still active (Table 1).

Interaction Between Stimulation of the Pressor and Depressor Areas on the Sciatic-Stimulation-Induced Spinal Reflexes

Lesion in the PRN regions vs. activation of the medullary pressor areas. Since very active inhibition of spinal reflexes was observed following electrical or chemical stimulation of the PRN area in the intact as well as in the chronically prepared cats after cerebella removal (9), the effects of PRN lesions subsequent to kainic acid on the DM- or VLM-induced EVRR inhibition were studied (Table 2). It was found that lesion in the PRN area on both sides did not affect spinal reflex inhibition due to VLM, PVC, or DM stimulation (Fig. 5).

Lesion in the medullary pressor areas vs. PRN activation. When lesions were produced bilaterally in either the VLM or DM by kainic acid or direct current, EVRR inhibition produced by PRN activation was significantly reduced and the reduction was substantially more marked after DM than VLM lesions; the inhibition remained 20.3 vs. $43.2 \%$ in $\mathrm{KnJ}$ or 15.0 v.s. $42.0 \%$ in cross extensor movement, respectively ( $\mathrm{Ta}$ ble 2$)$.
In a separate group of four cats subjected to PRN stimulation (not listed in Table 2), DM lesions converted the inhibition of the $\mathrm{KnJ}$ to a slight increase $(+30 \%)$ along with the conversion of the depressor to a mild pressor response (MSAP increased 12 $\mathrm{mmHg}$ ) in three of these four animals. In the remaining one animal, the DM lesion potentiated the $\mathrm{KnJ}$ inhibition from 65 to $100 \%$.

Effects of selectivell lesioning the pressor areas of the VLM or DM on the spinal reflexes induced by DM or VLM stimulation. Selectively lesioning the pressor areas of the VLM or DM decreased the spinal reflex inhibition due to DM or VLM activation. The decrease was substantially more marked but not statistically significant after VLM than DM lesions; inhibition remained 3 vs. $16.4 \%$ in EVRR (Table 2).

\section{DISCIJSSION}

The existence of a neuronal population in the areas of the VLM $(17,33,36)$, DM, and PVC $(8,21,25,27,29)$ involved in cardiovascular integration has been repeatedly demonstrated. The classic experiment of Bach (1) has shown a widely spread area in the medulla that produces respiratory, vasomotor, and $\mathrm{KnJ}$ changes in response to electrical stimulation. Using more refined methods of both electrical and chemical stimulation, the present experiment has shown that specifically localized areas within these medullary pressor sites have coexisting neuronal populations that also affect somatic spinal reflexes. Since the reflex mechanism is activated by excitatory amino acids, which excite perikarya and dendrites without affecting axons and the surrounding fibers of passage (22), the neuronal perikaryon nature of this somatic mechanism is suggested.

Furthermore, this medullary-spinal reflex mechanism does not depend upon the integrity of rostral neural structures for action inasmuch as midcollicular decerebration did not affect 


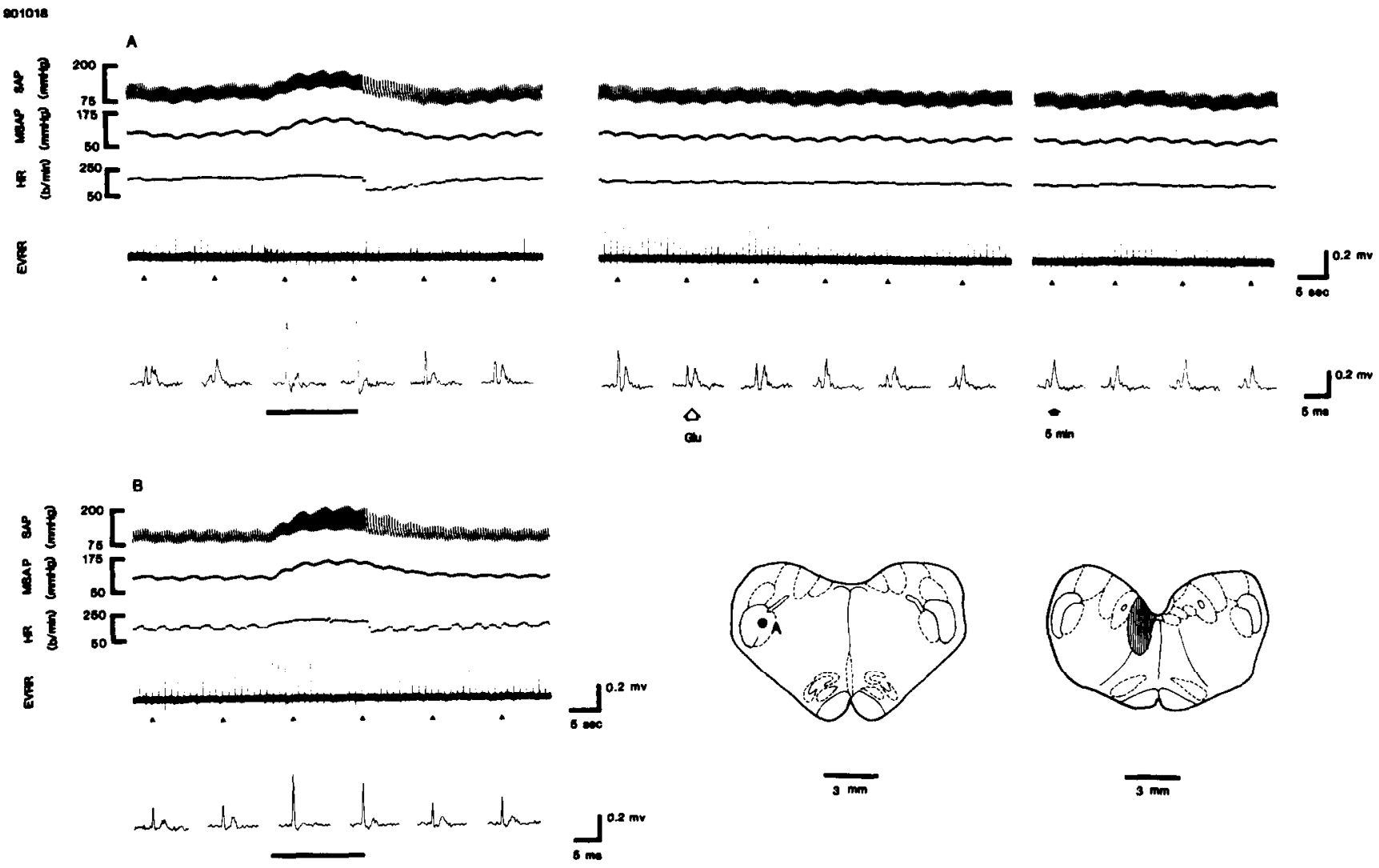

FIG. 7. Dissociation of vasomotor and spinal responses following electrical and Glu activation. Top panels (left) show that electrical stimulation $(150 \mu \mathrm{A})$ of a point $(\mathrm{A})$ at the midlateral portion of the spinal trigeminal nucleus caused an increase of SAP and augmentation of EVRR. Microinjection of Glu ( $100 \mathrm{nl}$ ) at this same point produced opposite effects of a slight decrease of SAP and EVRR (top panels, right). After destruction of the dorsomedial area of the medulla on the same side (DC $0.5 \mathrm{~mA} .20 \mathrm{sec}$ ), as shown by the hatched area of the brain drawing, the changes in SAP and EVRR still persisted (bottom panels, B).

the spinal reflex inhibition. Cerebella might affect spinal reflexes (2.3). Nevertheless. marked EVRR inhibition upon medullary stimulation was observed in cats whose cerebella had been removed longer than 10 days to allow a complete degeneration of the afferent and efferent fibers between cerebellum and medulla. This is consistent with our previous experiment, where in chronically decercbellated animals PRN stimulation similarly produced reflex inhibition (9).

Activation of the pressor areas in the medulla evokes marked hypertension and inevitably activation of the baroreceptor reflex. The induced inhibition of spinal reflexes, nevertheless, was not a result of baroreceptor activation because: 1) The inhibition could be produced in animals after sectioning the carotid sinus and vagoaortic nerves; 2 ) systemic administration of an $\alpha$-adrenergic blocking agent to eliminate the SAP rise during medullary stimulation did not change the magnitude of the reflex inhibition; 3) administration of a vasodilator, which caused a SAP decrease, uniformly inhibited the reflexes; 4) systemic administration of a pressor agent to cause an SAP increase produccd prcdominantly an excitation of the spinal reflex. In general, the effects of spinal reflexes are opposite to that of the SAP change subsequent to medullary stimulation.

The persistence of spinal reflex inhibition after elimination of the SAP rise during medullary stimulation is consistent with the report that the inhibition of somatosympathetic reflex consequent to activation of the lateral reticular nucleus was independent from baroreceptor inputs (18). In the medulla, vagal or baroreceptor components are located close together and can be activated simultaneously during medullary stimulation. However, the vagus component appears not to be essential inasmuch as the reflex inhibition elicited from medullary stimulation persisted after bilateral vagotomy.

The medullary pressor or depressor responses are dissociated from the spinal reflex. For instances, during medullary stimulation fast and marked spinal reflex inhibition was more readily observed in the pressor sites that produced a bigger pressor response to glutamate. Nevertheless, the degree of SAP rise was not necessarily the determinating factor for spinal reflex inhibition, but the location of stimulating loci was important (Fig. 5). The reduction of EVRR was not necessarily confined to the pressor area that elicits a rise in SAP because the activation of the depressor mechanism in DM that produced the SAP decrease also produced an EVRR reduction (Fig. 4). Stimulation of PRN produces an SAP decrease, yet elicits very marked reduction of the spinal reflex $(9)$.

The above, therefore, explains that these responses are caused by a dissociation in the medullary mechanism integrating somatic spinal reflexes and vasomotor action, no matter whether pressor or depressor. Indeed, Janss et al. (26) produced tail-flick due to stimulating the pressor area of the lateral reticular nucleus with a current that did not induce any pressor response or significant change in the resistance of various vascular beds. In other sites. stimulation with cur- 

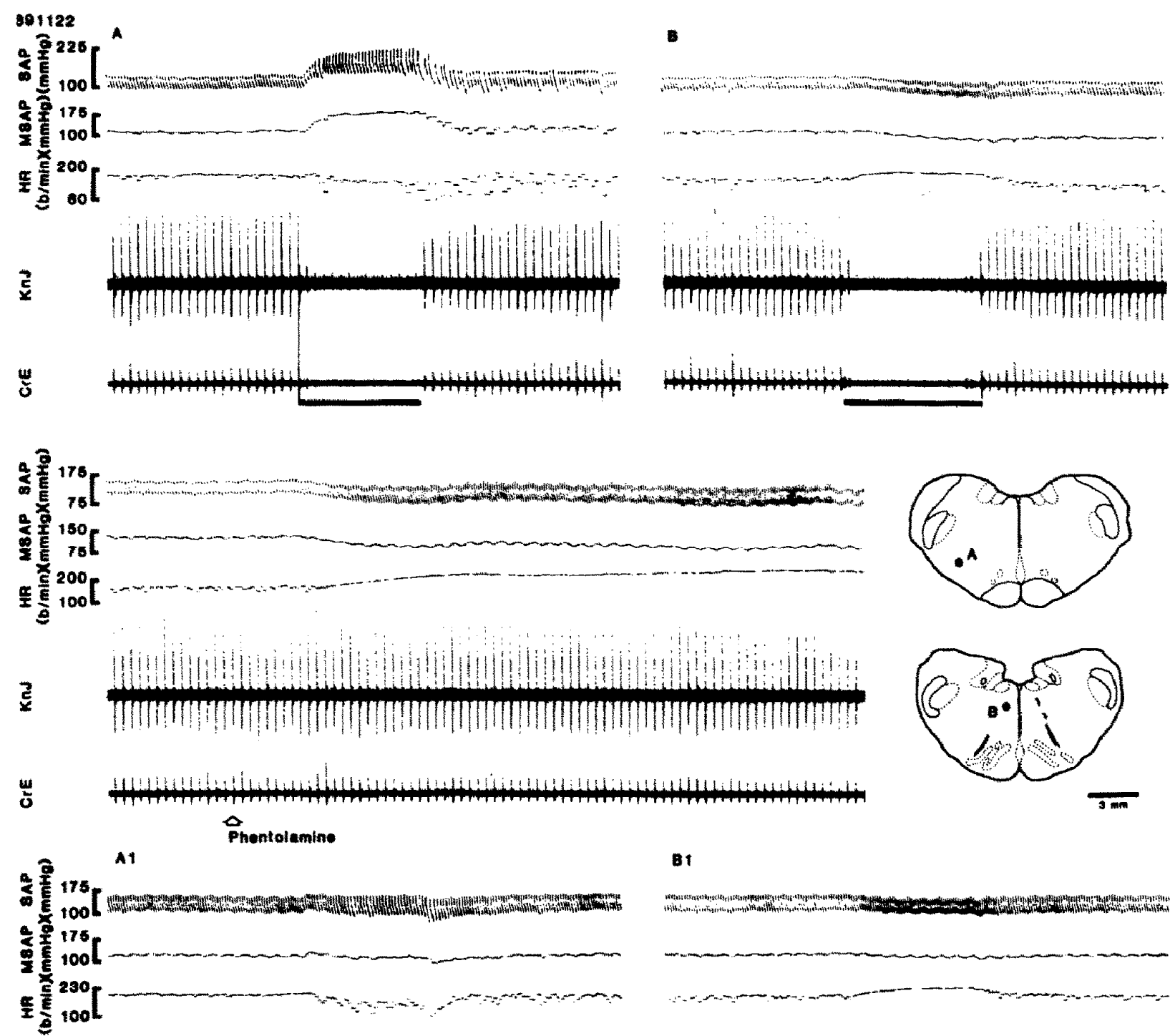

BI
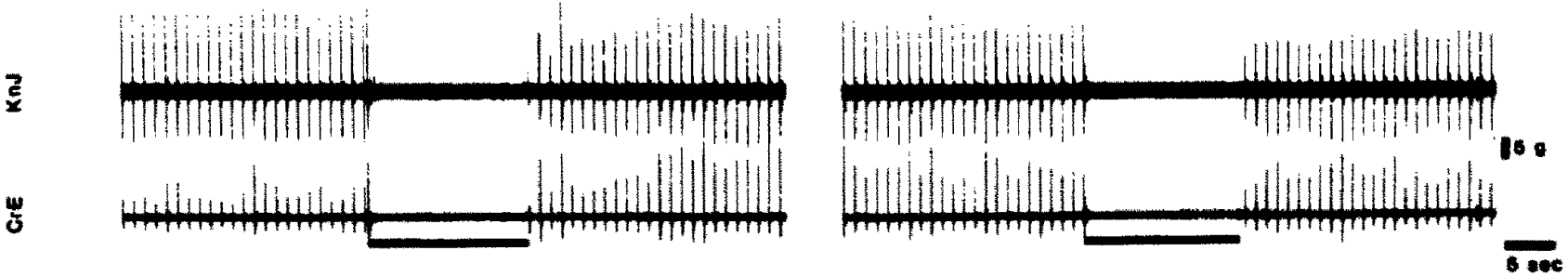

FIG. 8. Baroreceptor activation is not a cause of the inhibition of spinal reflex consequent to medullary stimulation. Top panels of the left, A, show that electrical stimulation $(100 \mu \mathrm{A})$ on a point $(\mathrm{A})$ in VLM, $4 \mathrm{~mm}$ rostral to obex as shown in the brain drawing, produced a marked elevation of SAP, bradycardia, and poststimulatory cardiac arrhythmia. Top panels of the right. B. show that stimulation (200 $\mu$ A) of a point (B) in PRN, $2 \mathrm{~mm}$ rostral to the obex, produced a slight SAP decrease. But, in both DM and PRN stimulations with the subsequent change of SAP in a opposite direction the knee jerk ( $\mathrm{KnJ}$ ) and crossed extensor movement (CEM) was completely inhibited. Middle panels show that following phentolamine $0.4 \mathrm{mg} / \mathrm{kg}$ IV despite a slight decrease of SAP (recovered $15 \mathrm{~min}$ later) the spinal reflex did not change. Bottom panels show that after phentolamine stimulation of the same points (A) at VLM and (B) at PRN produced the same reduction of spinal reflexes in the absence of SAP change.

rents of higher intensity, although producing increases of SAP and vascular resistance as predicted, when coupled with administration of glutamate produced an SAP decrease despite the induction of tail-flick. We also observed contradictory responses between electrical and glutamate stimulation in the same site of the DM or VIM $(8,30)$. In the three stimulation sites of the present study-two in the DM, one in the VLMelectrical stimulation produced marked SAP elevation and spinal reflex inhibition yet glutamate microinjection produced no SAP change but still an inhibition of the EVRR. Also, in six points in each VLM and DM from four cats electrical stimulation produced very marked SAP rises and EVRR ex- 
TABLE 2

INTERACTIONS BETWEEN STIMULATION OF THE PRN AND THE PRESSOR AREAS OF THE DM AND VLM ON SPINAL REFLEXES

\begin{tabular}{|c|c|c|c|c|}
\hline & \multirow[b]{2}{*}{ SAP Change $(\%)$} & \multicolumn{3}{|c|}{ EG Movement } \\
\hline & & Kal $(\%)$ & $\operatorname{CEM}(\%)$ & EVRR $(\%)$ \\
\hline \multicolumn{5}{|l|}{ PRN stimulation } \\
\hline Control & $-25.4 \pm 5.3^{*}$ & $-94.0 \pm 4.5^{*}$ & $-94.0 \pm 4.1^{*}$ & \\
\hline After VLM lesion $(n=6)$ & $-9.0 \pm 5.8 \dagger$ & $-43.2 \pm 16.2 *+\ddagger$ & $-42.0 \pm 18.1^{*}+t$ & \\
\hline Control & $-16.8 \pm 4.2^{*}$ & $-100.0 \pm 0.0^{*}$ & $-100.0 \pm 0.0^{*}$ & \\
\hline After DM lesion $(n=7)$ & $+2.1 \pm 7.7 t t$ & $-20.3 \pm 10.1+\ddagger$ & $-15.0 \pm 7.2 \dagger \ddagger$ & \\
\hline \multicolumn{5}{|l|}{ VLM stimulation } \\
\hline Control & $+44.6 \pm 12.7^{*}$ & & & $-46.5 \pm 20.0$ \\
\hline After PRN lesion $(n=5)$ & $+33.5 \pm 5.0^{*}$ & & & $-49.0 \pm 13.7^{*}$ \\
\hline Control & $+41.6 \pm 10.7^{*}$ & & & $-48.2 \pm 15.2^{*}$ \\
\hline After DM lesion $(n=5)$ & $+30.4 \pm 6.5^{*}$ & & & $-16.4 \pm 4.3^{*}+$ \\
\hline \multicolumn{5}{|l|}{ DM stimulation } \\
\hline Control & $+51.0 \pm 4.5^{*}$ & $-100.0 \pm 0.0^{*}$ & $-100.0 \pm 0.0^{*}$ & \\
\hline After PRN lesion $(n=6)$ & $+39.4 \pm 3.1^{*}$ & $-80.3 \pm 13.9^{*}$ & $-100.0 \pm 0.0^{*}$ & \\
\hline Control & $+57.2 \pm 7.6^{*}$ & & & $-48.8 \pm 6.7^{*}$ \\
\hline After VLM lesion $(n=6)$ & $+33.3 \pm 9.3^{*}$ & & & $-3.0 \pm 6.2+$ \\
\hline
\end{tabular}

citation; glutamate produced the same SAP rise but, instead, the EVRR was inhibited (Figs. 3 and 7). The latter event also indicates that the mechanisms responsible for inhibition and excitation of spinal reflexes are separate.

The lateral reticular nucleus of the VLM, which is an important mechanism for integrating cardiovascular functions, also exerts influence on somatic functions related to afferent inputs $(14,18,19,28,35)$ and somatosympathetic reflex $(15,24)$. The pressor area of the DM also has been suggested to be the site integrating somatosympathetic reflex $(16,25)$. DM lesioning resulted in an abolition of the late component of the evoked potential in the renal nerve after activation of various somatic afferent nerves (25). These data, our previous results $(6,8,10,29,30,38)$, and those of others $(17,23)$ support the fact that perikarya in the DM arca are responsible for the vasomotor action of this part of the medulla.

There are other structures in the brain stem facilitating somatic functions. Sites that cause facilitation of the cortical motor response (34) and $\mathrm{KnJ} \mathrm{(31)} \mathrm{have} \mathrm{been} \mathrm{found} \mathrm{in} \mathrm{the} \mathrm{whole} \mathrm{brain}$ stem including medulla. In the present study, sites that caused increased EVRR were mixed with the sites producing inhibition but occupied a location more rostrally, a finding consistent with the observation that stimulating the locus coeruleus facilitated monosynaptic reflexes (12).

The PRN is a structure that can produce marked inhibition of spinal reflexes (7). This nucleus responded to excitatory amino acids for both depressor response and spinal reflex inhibition, but the reactivity was much less in comparison with that of the VLM, DM, and PVC (7-9). This may be attributed to two possibilities: 1) The neuronal perikaryon responsible for spinal reflex inhibition does not utilize glutamate as a principal chemical agent for activation; 2) the number of neuronal perikarya are sparse in the PRN region of cats. The present experiment provides no information on this question.
But, by comparing the interrelationship among the PRN, VLM, and DM after lesioning each individual area it was found that after PRN lesions the spinal reflex inhibition due to VLM stimulation was not reduced. DM stimulation after PRN lesions did not reduce reflex inhibition in six animals, potentiation of the inhibition was observed in one animal, and conversion of the inhibition to augmentation occurred in three animals. Therefore, the results of PRN lesions are not consistent. On the other hand, after the VLM or DM was lesioned, particularly the latter, the spinal reflex inhibition elicited from PRN stimulation was substantially although not statistically reduced. Furthermore, when comparing the effects of lesioning the DM or VLM to the induced reflex inhibition by VLM or DM stimulation it was found that attenuation of the inhibition was more marked, although not statistically significant, after a VLM than a DM lesion. Similarly, more detrimental effects on the vasomotor reactivity of medullary stimulation were observed after VLM than DM lesions (38). As the DM and VLM are reciprocally related to cardiovascular integration (38), it seems possible that at least one of the fiber pathways from the PRN mediating spinal reflex inhibition might pass from the DM to the VLM. Further experimentation has to be done in this regard.

In summary, the present results demonstrate that in the pressor areas of the VLM, DM, and PVC neuronal perikarya responsible for cardiovascular integration coexist with a neuronal perikarya mechanism for affecting somatic reflex inhibition and excitation. The following possibilities might exist in the medulla and require further study: 1) The same perikarya that affect cardiovascular actions mediate noncardiovascular actions; 2) a separate group of perikarya is responsible for the noncardiovascular actions; 3) the noncardiovascular perikarya are activated either through direct synapses from the pressor perikarya or activated indirectly from the pressor 
perikarya through one or more interneurons; 4) the possibility exists that changes in spinal reflexes during medullary stimulation might be mediated through activation or inhibition of the medullo-spinal mechanism affecting the spinal afferent input (37) of the reflex arc.

\section{ACKNOWLEDGEMENTS}

We thank G. T. Chen for preparation of the illustrations and J. J. Pan for preparation of the manuscript. This study was supported in part by the Foundation of Biomedical Sciences, Institute of Biomedical Sciences, Academia Sinica, and the National Science Council, ROC, No. NSC 79-0412-B001-02.

\section{REFERENCES}

1. Bach, L. M. N. Relationships between bulbar respiratory, vasomotor and somatic facilitatory and inhibitory areas. Am. J. Physiol. 171: $417-435: 1952$.

2. Brodal, A. Recticulo-cerebellar connections in the cat. J. Comp. Neurol. 98:113-153:1953.

3. Brodal, A.; Torvik, A. Cerebellar projections of paramedian reticular nucleus of medulla oblongata in cat. J. Neurophysiol. 17:484-495; 1954.

4. Chai, C. Y. Coexistence of multiple functions in pressor areas of the dorsal and ventrolateral medulla. In: Hoffer, B. J.; Lee, H. K.; Wang, Y.. eds. Neuroscience research. Taiwan, ROC: NSC (ROC) NSF (US) Joint Scminar: 1990:21-24.

5. Chai, C. Y. Inhibitory actions of the paramedian reticular nucleus of medulla oblongata. American Physiological Society-Chinese Physiological Society Joint Meeting, S1-1:25; 1990.

6. Chai, C. Y.; Lee, T. M.; Wayner, M. J. Effects of visceral afferent activation on leg extension induced by sciatic afferent stimulation. Brain Res. Bull. 3:115-123;1978.

7. Chai, C. Y.; Lin, Y. F.; Lin, A. M. Y.; Pan, C. M.: Lee, E. H. Y.; Kuo, J. S. Existence of a powerful inhibitory mechanism in the medial region of caudal medulla - with special reference to the paramedian reticular nucleus. Brain Res. Bull. 20:515-528; 1988.

8. Chai, C. Y.: Lin, R. H.: Lin, A. M. Y.: Pan, C. M.; Lee, E. H. Y.; Kuo, J. S. Pressor responses from electrical or glutamate stimulations of the dorsal or ventrolateral medulla. Am. J. Physiol. 255:R709R717: 1988 .

9. Chai. C. Y.; Lin, Y. F.; Wang, S.; Wu, W. C.; Yen, C. T.; Kuo, J. S.; Wayner, M. J. Inhibition of spinal reflexes by paramedian reticular nucleus. Brain Res. Bull. 25:581-588; 1990

10. Chai, C. Y.: Wang, S. C. Localization of central cardiovascular control mechanism in lower brain stem of the cat. Am. J. Physiol. 202:2530; 1962.

11. Chai, C. Y.: Wang, H. Y.; Yen, C. T,; Kuo. J. S. The sympatheticpressor mechanism in dorsal and ventrolateral medulla also contain neuronal mechanism modulating somatic spinal reflex. Twenticth International Congress of Neurovegetative Res., F-05-03:67; 1990.

12. Chan, J. Y. H.; Fung, S. J.; Chan, S. H. H.; Barnes, C. D. Facilitation of lumbar monosynaptic reflexes by locus coeruleus in the rat. Brain Res. 369:103-109:1986.

13. Chiang, C. H.: Pappagianopoulos, P.; Hoop, B.; Kazemi, H. Central cardiorespiratory effects of glutamate in dogs. J. Appl. Physiol. 60 : 2056-2062. 1986.

14. Ciriello, J.; Calaresu, F. R. Lateral reticular nucleus: A site of somatic and cardiovascular integration in the cat. Am. J. Physiol. 233:R.100R $109 ; 1977$.

15. Coote, J. H.; Hilton, S. M.; Perez-Gonzalez, J. F. The reflex nature of the pressor response to muscular exercise. J. Physiol. (Lond.) 215; 780-804: 1971 .

16. Coote, J. H.: Wowdmman, C. B. B. Central pathways of some autonomic reflex discharges. J. Physiol. (Lond.) 183:714-729; 1966.

17. Dampney, R. A. L.; Moon, E. A. Role of ventrolateral medulla in vasomotor response to cerebral ischemia. Am. J. Physiol. 239:H349H358; 1980 .

18. Dembowsky, K.; Czachurski, J.; Amendt, K.; Seller, H. Tonic descending inhibition of the spinal somato-sympathetic reflex from the lower brain stem. J. Autonom. Nerv. Syst. 2:157-182;1980.

19. Dembowsky, K.; Lackner, K.; Czachurski, J.; Seller, H. Tonic catecholaminergic inhibition of the spinal somato-sympathetic reflexes originating in the ventrolateral medulla oblongata. J. Autonom. Nerv. Syst. 3:277-290; 1981 .

20. Elisevich, K. V.; Hrycyshyn, A. W.; Flumerfelt, B. A. Cerebellar, medullary and spinal afferent connections of the paramedian reticular nucleus in the cat. Brain Res. 332:267-282; 1985.
21. Goodchild. A. K.: Dampney, R. A. L. A vasopressor cell group in the rostral dorsomedial medulla of the rabbit. Brain Res. 360:2432: 1985

22. Goodchild, A. K.; Dampney, R. A. L.; Bandler, R. A method for evoking physiological responses by stimulation of cell bodies, but not axons of passage, within localized regions of the central nervous system. J. Neurosci. Meth. 6:351-363; 1982.

23. Gebber, G. L.; Barman, S. M. Lateral tegmental field neurons of cat medulla: A potential source of basal sympathetic nerve discharge. J. Neurophysiol. $54: 1498-1512 ; 1985$.

24. Iwamoto, G. A.; Kaufman, M. P.: Botterman, B. R.; Mitchell, J. H. Effects of lateral reticular nucleus lesions on the exercise pressor reflex in cats. Circ. Res. 51:400-403; 1982.

25. Iwamura. Y.: Uchino, Y.: Ozawa, S.; Kudo, N. Excitatory and inhibitory components of somato-sympathetic reflex. Brain Res. 16 : $35 \mathrm{t}-358 ; 1969$.

26. Janss, A. J.; Cox, B. F.; Brody, M. J.; Gebhart, G. F. Dissociation of antinociceptive from cardiovascular effects of stimulation in the lateral reticular nucleus in the rat. Brain Res. 405:140-149; 1987.

27. Janss, A. J.; Gebhart, G. F. Spinal monoaminergic receptors mediate the antinociception produced by glutamate in the medullary lateral reticular nucleus. J. Neurosci. 7(9):2862-2873; 1987.

28. Janss, A. J:: Gebhart, G. F. Brainstem and spinal pathways mediating descending inhibition from the medullary lateral reticular nucleus in the rat. Brain Res. 440:109-122; 1988 .

29. Lin. A. M. Y.; Wang, Y.; Kuo, J. S.; Chai, C. Y. Homocysteic acid elicits pressor responses from ventrolateral medulla and dorsomedial medulla. Brain Res. Bull. 22:627-631; 1989.

30. Lin, R. H; Lin, A. M. Y.; Su, C. K.; Kuo, J. S.; Chai, C. Y. Presence of perikarya for vasopressor actions in both the dorsal and ventrolateral regions of medulla oblongata in swine. Neurosci. Res. Comm. $5: 125-133 ; 1989$.

31. Magoun, H. W.; Rhines, R. An inhibitory mechanism in the bulbar reticular formation. J. Neurophysiol. 9:165-171; 1946.

32. Regier, M. H.: Mohapatra, R. N.: Mohapatra, S. N. Biomedical statistics with computing. Chichester: Research Studies Press; 1982.

33. Reis, D. J.: Ross, C. A.; Ruggiero, D. A.; Granata, A. R.; Joh, T. H. Role of adrenaline neurons of ventrolateral medulla (the $\mathrm{Cl}$ group) in the tonic and phasic control of arterial pressure. Chin. Exp. Hypertens. A Theory Pract. 6:221-241; 1984.

34. Rhines, R.; Magoun, H. W. Brain stem facilitation of cortical motor response. J. Neurophysiol. 9:219-229; 1946.

35. Rosen, I.; Scheid, P. Patterns of afferent input to the lateral reticular nucleus of the cat. Exp. Brain Res. 18:242-255; 1973.

36. Ross, C. A.; Ruggiero, D. A.: Joh, T. H.; Park, D. H.; Reis, D. J. Adrenaline synthetizing neurons in the rostral ventrolateral medulla: A possible role in tonic vasomotor control. Brain Res. 273:356-361; 1983.

37. Schramm, L. P.; Poree, L. R. Medullo-spinal modulation of sympathetic output and spinal afferent input. J. Cardiovasc. Electrophysiol. 2:S18-S25; 1991.

38. Su, C. K.; Lin, A. M. Y; Lin, R. H.; Kuo, J. S.; Chai, C. Y. Contribution between dorsal and ventrolateral regions of medulla oblongata in vasomotor function of cats. Brain Res. Bull. 23:447-456; 1989.

39. Wang. S. C.; Chai, C. Y. Central control of sympathetic cardioacceleration in medulla oblongata of the cat. Am. J. Physiol. 202: 31-34. 1962.

40. Zaczek, R.: Simonton, S.; Coyle, J. T. Local and distant neuronal degeneration following intrastriatal injection of kainic acid. J. Neuropathol. Exp. Neurol. 39:245-263, 1980. 